\title{
A POEIRA DO TEMPO E AS CIDADES TROPICAIS, UM ENSAIO INTERPRETATIVO DO PATRIMÔNIO E AS DINÂMICAS DA CULTURA EM SOCIEDADES COMPLEXAS.
}

Ana Luiza Carvalho da Rocha

\section{O pluralismo coerente da duração no interior das dinâmicas da cultura contemporânea}

Através de minha tese de doutorado que trata da poética da assimetria no nascimento da "civilização urbana" no corpo de uma América barroca ${ }^{1}$, este ensaio procura refletir sobre os aspectos relacionados ao tratamento da memória coletiva e do patrimônio etnológico que compõe a vida urbana no Brasil a partir da critica bachelardiana ao conceito de intuição da duração em M. BERGSON e da construção por este autor da intuição do instante como contraponto a idéia bergsoniana da duração como dado imediato da consciência.

Neste ensaio convidamos o leitor a pensar que o passado é uma "força real de causalidade" do tempo presente, para adotar a idéia de que o presente se configura como afirmação de uma seqüência de instantes cuja cadencia de propagação faz parecer sua condição temporal como contínua e homogênea. Esta preocupação aparentemente pontual sobre o tema da dialética da duração e da intuição do instante na obra de G. BACHELARD pode ser lida à luz das preocupações simmelianas a respeito dos caminhos que conduzem as formas sociais a se perpetuarem. Preocupações que considero ainda atuais na ordem do dia para se pensar o tema do patrimônio e das dinâmicas culturais. Segundo G. SIMMEL $^{3}$ o que desafia todo o sociólogo é a manutenção da vida social sendo que ela não contempla a mesma matéria dos fenômenos físicos. Para encaminhar uma resposta a seus problemas, este autor nos sugere que ao invés de se pensar a duração destes fenômenos sociais, mas na sua forma. Vejo aí, um convite a adentrarmos as reflexões bachelardianas sobre tempo e duração para pensar com G. SIMMEL as formas especificas pelas quais as sociedades enquanto tais se conservam, em particular a sociedade brasileira.

'. Segue-se aqui a análise já feita da arqueologia do gesto e das motivações simbólicas que fundam as cidades brasileiras, cf. ROCHA, A.L. C. Le Santuaire du désordre, ou l'art de savoir-faire des tendres barbares sous les Tristes Tropiques, Universidade René Descartes, Paris V, Sorbonne, junho, 1994.

${ }^{2}$ Cf. G. BACHELARD, L'intuition de l'instant. Paris, Denöel Gonthier, 1932, p .32.

${ }^{3}$ Nas palavras do próprio autor : les formes qu'affectent les groupes d'hommes unis pour vivre les uns à côté des autres, ou les uns pour les autres, ou les uns avec les autres, voilà donc le domaine de la sociologie, G. SIMMEL, Comment les formes sociales se mantiennet, In : Sociologie et èpistémologie. Paris, PUF, 1991, p. 172. 
Apoiando-me, portanto nas idéias de G. SIMMEL e de G. BACHELARD minha intenção é a reforçar, para os estudos da memória e do patrimônio, que o tempo presente se oferece como objeto de investigação interessante para a memória e o patrimônio uma vez que é nele que a pluralidade de durações de instantes descontínuos passa a ser fortemente agrupados pelas motivações simbólicas que orientam a experiência humana no seu mundo cósmico e social. A adesão à idéia bachelardiana da intuição do instante e da dialética da duração representa, aqui, uma possibilidade de se pensar a estética urbana "disforme", "monstruosa", "desordenada" do conjunto civilizacional das cidades brasileiras ("tropicais" como denomino na tese de doutorado) como resultado de certas condições temporais que as formas de vida de seus habitantes propagam em seus territórios e não apenas como condição espacial de sua existência.

Ao adotar a idéia de que se trata das formas de sociabilidade na vida urbana os lugares onde uma propagação singular de instantes adquirem força a ponto de se perpetuar, penso eu que o tema da unidade e da identidade de uma comunidade urbana (e neste ponto é que procuro refletir sobre o tema do patrimônio no interior das dinâmicas culturais no mundo contemporâneo) enfocaria precisamente nas condições temporais através das quais seu corpo coletivo se constitui como consciência de si no mundo no interior de uma pluralidade de instantes que configura sua vida.

Nesta perspectiva, penso as questões do patrimônio e da memória no interior dos hábitosritmos $^{4}$ que compõe as formas de sociabilidade, as trajetórias sociais, os itinerários urbanos e o cotidiano dos habitantes de uma grande cidade, abandonando-se a perspectiva de ambos resultem da estabilidade de um passado, numa interpretação mais ou menos substancialistas da matéria destas formas de vida social. Sem dúvida, toda a cidade nos moldes da Grande Tradição ocidental, imagina para si um passado e projeto um futuro, entretanto, em nossa abordagem de inspiração bachelardiana, diríamos que a matéria de ambos adquire solidez precisamente porque ambos se formam, no presente, como uma seqüência de instantes bem ordenados a ponto de lhes atribuir propriedades. O patrimônio como a memória coletiva são fenômenos que presidem precisamente esta esfera das condições temporais através das qual um corpo coletivo atinge sua perpetuidade como substância em meio a descontinuidades de instantes por ele vividas.

\footnotetext{
${ }^{4}$ Expressão retirada da analise que faz G. BACHELARD sobre o problema do costume e o tempo descontínuo, L'intuition de l'instant, op.cit., p.69. Podemos associar o que vem tratando aqui este autor com as reflexões de outro pensador J-M. BENOIT, Tyranie du logos, Paris, PUF 1993, em particular de seus comentários os lugares (propriedades) e nãolugares(impropriedades) do logos em sua relação com ser (l'être) - sede do pensar- e as questões filosóficas da irredutibilidade da linguagem e do pensamento a esfera do real
} 
Certamente podem me contestar argumentando não seriam então apenas as cidades "tropicais" 5 aquelas que apresentariam estas propriedades de uma matéria fluida, aérea, efêmera, mas toda a vida humana assim se expressaria. Tenho que concordar que o que estamos apresentando aqui se coloca como uma proposta de se re-pensar o tema da memória e do patrimônio amplamente, e não apenas para o caso das cidades brasileiras, entretanto, advogo que em determinados fenômenos sociais e culturais as regras formais de regulação temporal não se realizam plenamente, contraponde às motivações simbólicas de um tempo histórico e progressista.

O suposto é que os arranjos das formas de vida social (itinerários urbanos, formas de sociabilidade, trajetórias sociais, etc.) que se processam no interior das cidades brasileiras são tributários de estéticas singulares que marca estilos específicos do viver urbano segundo os jogos singulares de reverberação da memória entre seus habitantes. ${ }^{6}$ Viver a cidade no Brasil é sempre testemunhar o seu inicio, a sua fundação na forma como a inscrevo em minhas ações cotidianas, o que afastaria aqui a perspectiva materialista para a continuidade formal de seus patrimônios materiais ou imateriais.

Fruto deste estilo presenteista ${ }^{7}$ de viver a cidade, da solidariedade entre a voz do passado e o incerto do vir-a-ser no presente dos instantes vividos por cada habitante no interior dos territórios urbanos, decorre a estética da desordem e da monstruosidade que tanto impregna a imaginação da matéria terrestre para o caso paisagem das cidades no Brasil e sobre a qual eu irei me referir aqui no âmbito do debate sobre o tema do patrimônio e da memória para o caso das dinâmicas da cultura.

\section{As paisagens urbanas e o conjunto civilizacional das cidades brasileiras}

Retornando ao tema deste Fórum, neste ensaio estou empenhada em pensar tais fenômenos desde outra perspectiva, não hegemônica no campo da produção antropológica sobre os estudos de memória e patrimônio. Neste sentido, para o caso da interpretação do conjunto civilizacional das cidades brasileiras o tema do patrimônio e da memória abarcaria, assim, precisamente, o fato de que nelas as condições temporais de vida seus habitantes expressam amplamente o tema da continuidade do

\footnotetext{
${ }^{5}$ A propósito o emprego da expressão "tropical" trata-se de uma proposta de pensar as formas que adotam o conjunto civilizacional das cidades brasileiras desde a sua perspectiva da uma afecção paisagista segundo a qual o dinamismo da força da própria matéria terrestre dos Trópicos (suas imagens de exuberância, abundancia, majestade, excesso) desenha a superfície assimétrica das paisagens urbanas no Brasil. Sobre a presença destas imagens na historia da literatura e do pensamento social do Brasil ver J. THEODORO, América barroca, temas e variações, SP, EDUSP, 1992, F. SUSSEKIN, O Brasil não é longe daqui. SP, Cia. da Letras, 1990; R. VENTURA, Estilo Tropical, SP, Cia. das Letras, 1991 e S. BUARQUE DE HOLLANDA, Visões do paraíso, Rio de Janeiro, José Olympio, 1968.

${ }^{6}$ Cf. ROCHA, A.L.C. A irracionalidade do belo e a estética urbana no Brasil. In: Territórios do cotidiano, uma introdução a novos olhares e experiências. Z. MESQUITA \& C. R. BRANDÃO (orgs) Editora UFRGS, Porto Alegre, 1995.

${ }^{7}$ Cf. A expressão é empregada por M. MAFFESOLI, La conquête du présent. Paris, PUF, 1994, a respeito do trágico social para tratar da organicidade entre vida e morte para a interpretação da tonalidade melancólica dos arranjos de cotidianos da vida social, em particular no mundo urbano contemporâneo
} 
descontinuo em seus hábitos-ritmos. Isto porque a cidade em suas propriedades de fenômeno urbano na imobilidade de suas formas não se apresentarem como uniformidade realizada em termos de condições espaciais

As cidades "tropicais" me permitem pensar, assim, as exuberâncias e riquezas de um tempo descontínuo, do tempo presente como um arranjo de instantes que restituem a um corpo coletivo sua substancia atual, e as incertezas que ele gera naqueles que não responsáveis pela condução do próprio conjunto civilizacional das cidades moderno-contemporâneas. Ou seja, não se trata de pensar o tempo passado ou o tempo futuro, trata-se sim de refletir das dinâmicas da cultura e no seu interior, e se pensar o patrimônio e a memória como instancias ou não de continuidade formal um corpo coletivo.

$\mathrm{Na}$ trilha da compreensão da polifonia das formas temporais através da qual a memória e o patrimônio constituem a estética da desordem ${ }^{8}$ no interior da vida social das grandes sociedades urbano-industriais4, como parte integrante dos pesquisadores do BIEV, elegemos Porto Alegre como laboratório de pesquisa de uma cultura urbana "tropical", em sua trajetória de desvio a propósito de uma estética da harmonia, profundamente moralista baseada nas imagens da ordem e do equilíbrio para os arranjos dos fenômenos da vida social no seu interior.

Neste percurso, um dos desafios tem sido compreender o complexo quadro que orientam as ações culturais dos poderes públicos no que tange as políticas de valorização dos bens tangíveis e intangíveis do mundo urbano brasileiro e as suas dificuldades em operar com o contexto de superposição espaço-temporal que marca a vida urbana no Brasil. Outro desafio diz respeito às possibilidades de se explorar novas formas de registro e documentação e narração das memórias coletivas e do patrimônio etnológico no mundo urbano contemporâneo local, através das novas tecnologias e dos recursos audiovisuais.

Conforme postulo em minha tese de doutorado, o trajeto antropológico da consolidação da civilização urbana sob os Trópicos coloca em jogo as emoções e as paixões coletivas confusionais arcaicas dos instantes que fundaram o querer-viver coletivo no Novo Mundo ao lado da visão linear e mecanicista do mito do Progresso para o caso do arranjo das suas formas de vida social no seu interior. Emoções e paixões associadas à matéria terrestre dos Trópicos e que acompanharam desde os tempos

\footnotetext{
${ }^{8}$ Apoio a reflexão sobre a estética da desordem no termo estética amplamente empregado por M. MAFFESOLI, Le paradigme esthétique, la sociologie comme art. In: Sociologie et Sociétes, V. 2, p.33-39, out. 1995, para pensar a própria produção do conhecimento sociológico em sua adesão a ordem sensível presente no interior da vida social, com forte inspiração da obra de G. Simmel.
} 
imemoriais os gestos fundacionais ${ }^{9}$ de sua apropriação territorial, e cuja continuidade sempre foi ritmado pelo tempo descontinuo dos encontros, confrontos e desencontros entre civilizações. ${ }^{10}$

Neste domínio de conhecimento, há toda uma bibliografia clássica que reconhece na descontinuidade temporal um caráter marcante da formação da sociedade brasileira. Apoiando-nos nesta bibliografia, o que insisto em pontuar aqui é precisamente que esta marca do tempo descontínuo para a duração do corpo coletivo, no caso da sociedade brasileira (e que está presente em outras tantas sociedades, mas não como forma expressiva de si) é que se revela para mim como possibilidade de sua continuidade formal, pois nela posso observar todo o esforço desse corpo coletivo para, desprovidos de certezas, re-estabelecerem, diuturnamente, sua possibilidade de existência no tempo. As cidades brasileiras, como conjunto civilizacional, vai se nutrir desta experiência coletiva cotidiana com a descontinuidade temporal dos instantes.

A ambigüidade das imagens iniciais da conquista da matéria terrestre nos Trópicos nos período das cidades coloniais e das cidades imperiais vai ser re-inventada no espaço das grandes cidades democráticas, moderno-contemporâneas. Por um lado, as cidades brasileiras (situadas no litoral, como Rio de Janeiro, Salvador, Olinda, etc. ou no sertão, Ouro Preto, Goiás Velho, Brasília, como as situadas ao longo de trechos de rios, montanhas e lagos, o caso de Porto Alegre, São Paulo, etc.) assentadas em sítios geográficos privilegiados sempre aludem à marca luxuriante arcaica da paisagem sugerida pela "natureza" dos Trópicos. Por outro, suas formas informes, ininterruptamente alteradas através do sacrifício constante da matéria terrestre apelam sempre para o eterno desejo da sua domesticação pelo homem da civilização. ${ }^{11}$ Morros e praias, morros e rios, rios e florestas, as cidades brasileiras oriundas da conquista da mãe-terra nos Trópicos acoplam a esta paisagem natural as belas, mas nem por isto boas e funcionais, obras humanas dos viadutos, das avenidas, dos túneis, dos arranha-céus, etc. Justamente pela feição de suas formas informes ${ }^{12}$, a Cidade no Brasil não adquire valor estético por

\footnotetext{
${ }^{9}$ Ao enfocar a arqueologia dos gestos (do Conquistador, do Missionário, do Tropeiro e do Imigrante) que sustentaram a instalação de uma civilização urbana no sul do Brasil, pude observar o quanto à sobreposição de estruturas espaçostemporais de tais gestos e suas técnicas (cidade-fortaleza, cidade santa, cidade-labirinto, cidade-entreposto) atuam na sua configuração como sistemas descentrados, onde geralmente o centro cósmico da memória coletiva não corresponde ao meio de seu território geográfico (nem tampouco ao meio do território nacional)

${ }^{10}$ Ver a respeito toda uma literatura do pensamento social brasileiro tais como G. FREIRE Maîtres et Esclaves, la formatiom de la société brésilienne. Paris, Gallimard, 1974, Sobrados e Mocambos, Vol. I e II. SP, José Olimpio, 1985, Interpretação do Brasil. Rio de Janeiro, José Olímpio, 1947.; R. DAMATTA, A casa e a rua e Carnavais, Malandros e Heróis, M. I. PEREIRA DE QUEIROZ, S. BUARQUE DE HOLLANDA, As Visões do Paraíso. os motivos edênicos no descobrimento e na colonização do Brasil. São Paulo, CIA.ED. Nacional, 1977 e Raizes do Brasil. São Paulo, José Olympio, 1968, G. VELHO, Individualismo e Cultura, R. OLIVEN, Violência e Cultura no Brasil, Petrópolis, Vozes, 1982; ORTIZ, R. A moderna tradição brasileira, cultura brasileira e industria cultural. São Paulo, Brasiliense, 1988; BASTIDE, R. Brasil, terra de contrastes. São Paulo, DIFEL, 1964, PEREIRA DE QUEIROZ, M.I. Cultura, Sociedade Rural, Sociedade urbana no Brasil, ensaios. São Paulo, EDUSP, 1978, MORSE, R. O espelho do próspero. São Paulo, Cia. das Letras, 1988, entre outros.

${ }^{11}$ A propósito ver. N. ELIAS e seu conceito de paisagem na obra La société des individus. Paris, Fayard, 1991

${ }^{12}$ Expressão original empregada por DORFLES, G. na obra Elogio da desharmonia. Lisboa, Martins Fontes, Ed.70, 1988.
} 
suas obras cultivadas, mas sim por uma concepção diferente da matéria da vida urbana atribuída à sensibilidade coletiva de seus habitantes e que se propaga através das formas de sociabilidade, das trajetórias sociais, dos itinerários urbanos e dos saberes e fazeres de seus habitantes em seus territórios (cujos hábitos e tradições não são nem sólidos, nem duráveis o suficiente para impedir que o novo se organize no seu interior). Parafraseando G. BACHELARD, neste momento é que se pode ver uma cidade "se inventar no tempo ao invés de se inventar no espaço". ${ }^{13}$

No Brasil, as paisagens das planícies, dos vales, das montanhas; dos rios, dos campos cultivados, das matas e das florestas mesclam-se as paisagens dos vilarejos, as cidades, os casarios, os edifícios, as malocas e suas vias de comunicação, as vielas, as ruas, as avenidas, etc. A configuração de um décor e de uma ambiência urbana e industrial disforme pelo processo contínuo de destruição e recriação só pode ser enfocada enquanto realidade material (em suas estruturas espaciais) penso eu que as paisagens urbanas no Brasil só pode perpetuar caso seus habitantes a reconquistarem cotidianamente em seus sonhos e devaneios.

Neste ponto, comparativamente a outras cidades (primordialmente as cidades européias), aquelas do Velho Mundo (que dormem docemente o sono da morte, para retomar uma expressão de C. LÉVISTRAUSS $^{14}$ ), a civilização urbana no Brasil adquire valor estético precisamente naquilo que ela evoca como território veicular, gerada na fruição de manifestações culturais de matizes diversos e de encontro de diferentes comportamentos estéticos. Interpretada sob o angulo das interconexões entre os domínios da estética urbana e da memória coletiva, a ambiência de caos e desordem encontra significado no encadeamento complexo de movimentos rítmicos desta gênese recíproca entre gesto pulsional do corpo coletivo no Brasil e o seu ambiente cósmico na perspectiva de um arranjo no tempo.

Os conjuntos urbanos no Brasil trazem, assim, em si as marcas de um tempo acelerado, muitas vezes precedido das intimações do ambiente social de uma história unilateral e triunfante. Por outro lado, sob o plano da memória coletiva tais conjuntos são os testemunhos de uma longa duração, quase imóvel - uma história de conquistadores na América em suas relações estreitas com a terra que os abrigou e os nutriu.

A proposta não é se propor aqui uma oposição natureza-cidade e homem-cidade em referência ao corte ontológico entre o homem e o Cosmos como fruto da ambiência psicosocial da Modernidade projetada sobre as cores tropicais. Mesmo considerando uma reflexão sobre o desequilíbrio patológico

\footnotetext{
${ }^{13}$ Cf. G. BACHELARD, L'intuition de l'instant. Paris, Denöel Gonthier, 1932, p. 69.

14 No original, C. LÉVI-STRAUSS, Les Tristes Tropiques, . Paris, Plon, 1955, Coll. Terre Humaine: "Certaines cités d'Europe s'endorment doucement dans la mort; celles du Nouveau Monde vivent fiévreusement dans une maladie chronique; perpétuellement jeunes, elles ne sont pourtant jamais saines."
} 
no homem da civilização nos Trópicos, cercado de uma cintura de fabricas, de favelas, de aranhas-céu, de fome e de miséria, de uma rede de vias utilitárias, a cidade "sem forma" encontra sempre, enquanto realidade vivida, as figuras diversas que encarnam a imagem de um território refúgio.

E necessário nos darmos conta do vinculo simbólico complexo que existe ente a construção de uma civilização urbana e industrial no Brasil que remonta a construção da casa onírica do homem brasileiro e os atributos telúricos dos Trópicos como a descoberta do Paraíso perdido. A civilização urbana e industrial no Brasil herdou todos os dilemas da formação do Estado-nação nos Trópicos, este lar do povo brasileiro que nos envia a forma como uma comunidade, através de um processo de consolidação de seu corpo coletivo, se perpetuou no espaço e no tempo. Ou seja, as cidades democráticas brasileiras cresceram e se complexificaram à sombra das seduções do "sentimentalismo" moral que emana do passado distante da implantação de uma Civilização no Novo Mundo.

$\mathrm{Na}$ ambiência psicosocial que orientou o mito de fundação da Cidade democrática já se podia encontrar a operação mortífera de destruição das texturas microscópicas dos tecidos urbanos plurais das antigas cidades brasileiras coloniais e imperiais. A destruição das antigas paisagens urbanas já trazia em si a promessa da superação definitiva das tribulações temporais vividas pelo corpo coletivo do Brasil de fins do século XIX.

Viajando ainda mais no tempo para encontrar os primeiros vilarejos (entre entradas e bandeiras), aonde a vida urbana que viria se desenvolver no coração dos Trópicos, já se pode perceber a rítmica do ciclo de mutilações e renascimento que deram origem a implantação de uma civilização urbana e industrial no Brasil, eternamente seduzida pela tentação das aspirações purificadoras e monárquicas do Herói civilizador nos Trópicos.

Por outro lado, a instabilidade das formas da vida urbana do país pautada pela aceitação de uma agitação temporal exprime esteticamente a forma como os povos autóctones metabolizaram o potencial mortífero do Estrangeiro na América tropical. Os rituais sacrificiais a que submetemos hoje a Cidade têm aqui um sentido litúrgicos e iniciáticos onde um corpo coletivo, pela repetição do sacrifício de suas estruturas espaciais "troca", "negocia" o passado contra o futuro, numa tentativa de domesticar Kronos.

A destruição no coração dos jogos da memória tem, portanto, uma natureza sintética: significa a maturação do fim dos Tempos e, ao mesmo tempo, possibilidade de atingir com ela imortalidade prometida. Industrialização, modernização e urbanização expressam assim muitos mitos cíclicos e operatórios de processos de mundialização das culturas: acelerar a história e domesticar o tempo é algumas de seus devaneios. Resistindo ao reducionismo de um tempo finalizado, as cidades resistem a este processo de mundialização, assim, permanecem fiéis a uma visão pluralista do tempo (talvez disforme e monstruoso aos olhos de muitos), único modo de preservar nelas mesmas a 
consagração da ordem polissêmica do corpo coletivo de seus habitantes e de incluí-los, no seu ventre ainda que degradando em muitas circunstancias a figura humana.

\section{O imaginário coletivo no mundo urbano como força da continuidade das paisagens} citadinas

Por sua tendência ao informal, a assimetria e à amplificação das suas formas, o teatro da vida urbana brasileiro concentra a variação de um Idêntico tanto quanto a Identidade dos diferentes através do gerenciamento de fórmulas repetitivas opostas ${ }^{15}$. Nas cidades brasileiras as acomodações e assimilações dos tempos locais e do tempo global formam arranjos inusitados aos olhos de um estrangeiro. Este traço marcante das cidades brasileiras me obriga a re-colocar o tema da paisagem e do patrimônio, no interior das dinâmicas da cultura que aí se apresentam, necessariamente em outros termos.

O patrimônio das cidades brasileiras resulta da potencia subterrânea de um corpo coletivo provocar, no cotidiano, a reverberação de certas formas de vida social de outrora, na materialidade de instantes fugazes do presente, em sua tensão com o instante futuro. Pensar o patrimônio é refletir as propriedades que adotam uma comunidade diante da abertura do seu devir; o passado aqui não se trata de um substancia que permanece latente e que ao longo da duração de um instante adquire propensão para renascer. O passado é verdadeiramente uma matéria confusa, informe, incerta que o instante presente esta encarregado de atualizar como tempo desaparecido.

A sociologia das formas de Georg SIMMEL, afirma que qualquer fenômeno da ordem da cultura (aqui no caso, o fenômeno temporal da memória e do patrimônio) possui uma manifestação concreta e precisa que é a sua "forma" captada na exterioridade de um arranjo.

Em termos da imaginação simbólica, o tempo cíclico tem no circulo sua forma mestra, o tempo histórico tem na flecha situada horizontalmente sua feição singular, o tempo progressista tem na flecha posicionada verticalmente sua expressão plena, etc. A riqueza das modalidades simbólicas de controle do caráter granular e nodular do tempo construída pelas sociedades humanas, diante da intuição de seus instantes descontínuos, é uma marca das marcas de sua existência espacial.

Pensar neste contexto interpretativo do imaginário coletivo no mundo urbano a continuidade das paisagens citadinas em suas marcas de descontinuidade é para o caso das cidades tropicais um desafio. Diante dele, opto por trabalhar pensar as cidades, suas paisagens e seus territórios desde a perspectiva

\footnotetext{
${ }^{15}$ R. OLIVEN, A parte e o todo, SP, Ed., Vozes e G. VELHO, Individualismo e Cultura, RJ, Zahar, 1981. Interessante poder enfocar esta temática a partir de alguns comentários de R. BOUDON, La place du désordre, Paris, PUF sobre as criticas as teorias da mudança social e de seus preconceitos nomológicos e ontológicos para pensar os conflitos,a incoerências e as tensões no interior da vida social .
} 
de uma geografia fantástica ${ }^{16}$, no cruzamento entre o tempo vivido e o tempo pensado acumulado por uma comunidade urbana ${ }^{17}$.

Toda a cidade desde o ponto de vista da função fantástica que a memória coletiva de seus habitantes agencia, para além de seus contornos físicos e concretos, engendra um espaço poético resultado dos sonhos e dos devaneios de seus habitantes e que orientam a sua descida no ventre de seus territórios ao longo do tempo ${ }^{18}$. Nesta perspectiva é que se re-descubro, acompanhada de P. SANSOT, da cidade como objeto temporal mais do que uma duração dada na concretude imediata de sua realidade espacial. Prefiro abordar a feição material e edificada de uma cidade como o produto do trajeto antropológico do imaginário, ou seja, o fruto lento da assimilação e acomodação dos gestos e motivações de seus habitantes em face do meio cósmico e social. ${ }^{19}$

Como objeto temporal, podemos sentir as paisagens urbanas "tropicais" segundo a solidariedade entre as múltiplas modalidades simbólicas de controle do tempo que marcam uma cidade como topos de um dinamismo criador de imagens, pois como já afirmei anteriormente nem todas as cidades adotam para si, no agenciamento do tempo, formas estáveis. Cidades como as brasileiras marcadas pelo acumulo vertiginoso do tempo em seus territórios, decorrentes de profundas transformações nas suas formas da vida social e cultural, retém em sua afecção paisagística, por estas mesmas razões, "formas" subjacentes e implícitas muito mais abstratas. ${ }^{20}$

Sou afetada pelas paisagens urbanas tropicais precisamente pelo ardor, a indocilidade, a vulnerabilidade de suas feições, fenômenos que contribuem para que os territórios das cidades brasileiras sempre fujam aos modos das épocas especificas nas quais se suas edificações se originaram, resultando disto as imagens de uma Cidade-ruína, sobreposição de fragmentos de formas espaçostemporais distintas. Um exercício interessante da afecção paisagista que os grandes centros urbanos do Brasil provocam é pensar os confins das suas cidades brasileiras, onde nascem e onde morrem do ponto de vista dos jogos da memória com os quais se movem seus habitantes na vida cotidiana. Algo que pode ser penoso de ser revelado numa cidade como Paris, Londres, Berlin como outras tantas cidades européias, por exemplo, torna-se evidente para o caso dos estudos sobre memória e duração das cidades

\footnotetext{
${ }^{16}$ Cf. expressão cunhada por G. DURAND, Les structures anthropologiques de l'imaginaire. Paris, DUNOD, 1984.

${ }^{17}$ Ambas as expressões apropriadas de Cf. G. BACHELARD, La dialectique de la durée 1989, Paris, PUF.

${ }^{18}$ Cf. G. BACHELARD, La poétique de l'espace, Paris, PUF, 1989, assim como a obra de Pierre SANSOT, seu discipulo, Les formes sensibles de la vie sociale, Paris, Klincksieck, 1986, La poétique de la ville, Paris, Klincksieck, 1972. Em particular seu artigo L'affection paysagère, In: Mort du paysage? Philosophie et esthétique du paysage. (org). François DAGOGNET. Champ Vallion, Seussel, 1982, onde o autor o papel da afetividade, do dinamismo recôndito do sensível no interior da matéria terrestre. Seguindo seu mestre, o olho e a mão humana para P. SANSOT não se constroem paisagens para atenuar a violência com que a matéria do mundo lhe interroga, bem ao contrario, o mundo é uma reserva infinita de paisagem precisamente pelo que a matéria terrestre impõe a nossa imaginação criadora.

${ }^{19}$ Cf. G. DURAND, Les structures anthropologiques de l'imaginaire, Paris, DUNOD, 1984, p. 38.

${ }^{20}$ Ver a respeito P. SANSOT, Les formes sensibels de la vie sociale. Paris, Gallimard, 1986 e A. Henri FUCILLON vida das formas. Lisboa, Edições 70, sd.
} 
brasileiras. Estou sujeita aqui a ser contestada em minha argumentação, pois precisamente são, em sua maioria, cidades atingidas por processo imensos e irreversíveis de destruição e aniquilamento em razão da Segunda Grande Guerra (à exceção de Paris).

Entretanto, importante se ressaltar que são cidades reconstruídas sob os escombros de uma memória injuriada, elas próprias grandes agenciadoras das idéias de patrimônio arquitetônico e da memória monumental, ou seja, do excesso de memórias que muito tempo inspirou, no Brasil, o tombamento de prédios, edificações e conjuntos arquitetônicos no interior dos territórios urbanos de nossas cidades. Cidades que contrastam com as nossas cidades "tropicais" que do ponto de vis as por um povo sem memória. Neste sentido, basta que se reflita nas diferentes modalidades simbólicas ta dos benefícios das descontinuidades dos instantes são eternamente jovens, pouco solidárias dos vestígios edificados de um tempo passado, ditas e vistas como sendo habitad de controle do tempo encontradas por estas comunidades urbanas assim como as nossas comunidades urbanas para trabalhar a ordem descontínua do tempo para se reconhecer as diferenças entre ambas.

Do ponto de vista da racionalidade do Cogito cartesiano do urbanista, do arquiteto e até mesmo do sociólogo e do prisma da extensão da matéria terrestre (sua exterioridade), dos confins de uma cidade fazem parte seus limites exteriores, físicos e geopolíticos. Entretanto, do ponto de vista interno aos jogos das memórias de seus habitantes, os limites de uma cidade articulam e graduam as relações de seus habitantes entre o que lhe é exterior e interior, definindo sua abertura e fechamento em relação ao mundo cósmico a partir dos símbolos de que regem a personalidade ética e o comportamento estético que funda sua comunidade. ${ }^{21}$

\section{O monstruoso e o disforme, o hibridismo das formas nas paisagens urbanas brasileiras.}

Neste sentido, inspirada nos jogos da memória ${ }^{22}$ e guiada pela experiência do tempo vivido de seus habitantes, me defronto com os limites da lógica patrimonial na interpretação, registro e documentação das paisagens urbanas das cidades brasileiras e onde as imagens do Idêntico e do Simétrico tendem a ignorar o hibridismo de formas culturais que orientou o gesto de configuração de tal conjunto civilizacional na América tropical, sempre pautada pela presença perturbadora da figura do Estrangeiro, nos termos de G. SMMEL. ${ }^{23}$

${ }^{21}$ Emprego aqui a expressão de A.LEROI-GOUHRAN, Le geste et la parole, Paris, Albin-Michel, 1965, Vol. La mémoire et les rythmes..

22 JEUDY, P.H. As memórias do social. Rj, Forense Universitária, 1990.

${ }^{23}$ G. SIMMEL The stranger. In: The Sociology of Georg Simmel. From Kurt Wolff (Trans.) New York: Free Press, 1950, pp. 402 - 408, em seu ensaio sobre a figura do Estrangeiro, como estranho e desconhecido, propõe uma interessante fórmula para se pensar o próximo e o distante como parte constituinte das relações das cidades brasileiras com o Tempo desde a sua formação, inspiradas na forma da técnica da viagem das quais elas são o fruto sob os Trópicos. Segundo o autor (1950:402): If wandering is the liberation from every given point in space, and thus the conceptional opposite to fixation at 
Contrariamente ao nascimento de muitas cidades medievais na Europa ${ }^{24}$ que funcionaram por muito tempo como sistemas centrados e fechados, cujos perímetros implicavam a existência de um centro, centro que coincidia com o meio, a civilização urbana no Brasil configurou-se, dessa maneira, na repetição arrítmica de temas, de lugares, de cenários-tipos, de encenações-tipo, de serialidade de acontecimentos oriundos das utopias de uma Europa renascentista.

Atuando enquanto sistemas descentrados, inúmeras cidades brasileiras desde seu gesto fundacional aprenderam com a peregrinação de pessoas na busca de melhores condições de vida para si e seus descendentes a acomodar as forças que exerciam pressão do interior para fora de seus limites, gerando paisagens urbanas marcadas por harmonia tensional entre perímetro-fronteira-confim. ${ }^{25}$

Pode-se constatar ainda hoje que as imagens veiculadas pela própria mídia televisiva e impressa em nossas modernas cidades urbano-industriais e as discursividades que geram sobre o medo, a violência e a criminalidade são herdeiras do mito de fundação da civilização urbana nos Trópicos que gravita em torno idéia de Excesso (etimologicamente: ex-cedere, ir para além de). O semantismo dos símbolos do Excesso para se pensar quais seriam os confins das grandes cidades brasileiras retorna com igual força a perpetuar sua matéria no período do carnaval, das grandes comemorações esportivas ou das grandes festas religiosas populares quando o caráter orgástico e desproporcional das paisagens urbanas se transfigura, agora, em potencia positiva para o corpo da sociedade brasileira. Para o bem ou para o mal, desde os seus mitos de fundação e seus personagens (Bandeirantes ou Tropeiros, Santos e Padres, Nobres e Guerreiros, Imigrantes, Escravos ou Colonos, Índios e Mamelucos, Malandros) ${ }^{26}$, portanto, as cidades brasileiras tendem a honrar as imagens do Excesso, pela característica de seus habitantes em atuar fora do limite de seu sistema físico-geográfico, sempre em alusão matéria terrestre

such a point, the sociological form of the "stranger" presents the unity, as it were, of these two characteristics. This phenomenon too, however, reveals that spatial relations are only the condition, on the one hand, and the symbol, on the other, of human relations. The stranger is thus being discussed here, not in the sense often touched upon in the past, as the wanderer who comes today and goes tomorrow, but rather as the person who comes today and stays tomorrow.

${ }^{24}$ A propósito ver MUNFORD, L. A cidade na história, suas origens, transformações e perspectivas. Lisboa, Martins Fontes, 1982.

${ }^{25}$ A propósito ver toda uma bibliografia sobre as teorias do desenvolvimento, da modernização e da mudança social bem como seus críticos representados por expoentes tais como L. PEREIRA, Ensaios de sociologia do desenvolvimento. SP, Pioneira/MEC, 1975, C. PRADO JR., História e Desenvolvimento. SP, Brasiliense, 1972, F.H. CARDOSO \& E. FALETTO, Dependência e Desenvolvimento na América Latina. RJ, ZAHAR, 1975, F. FERNANDES, Capitalismo dependente e classes sociais na América Latina. RJ, ZAHAR, 1973, J.de S. MARTINS, Capitalismo e tradicionalismo, estudo sobre as contradições da sociedade agrária no Brasil. SP, Pioneira, 1975, P. SINGER, Desenvolvimento econômico e evolução urbana no Brasil. SP. Ed; Nacional, 1968, entre outros.

${ }^{26}$ Ver à respeito algumas obras clássicas do pensamento sociológico brasileiro MOOG, V. Bandeirantes e Pioneiros. Rio de Janeiro, Civilização Brasileira, 1966, O.VIANA, Evolução do Povo Brasileiro. SP, Cia. Ed. Nacional, 1938 e Populações meridionais do Brasil, Vol II, O campeador. Rio de Janeiro, 1952, S.B. de HOLlANDA, Raizes do Brasil. SP, José Olympio, 1968 e Caminhos e Fronteiras, SP, Cia das Letras, 1994, M.I. PEREIRA DE QUEIROZ, Os cangaceiros: bandits d'honneur brésiliens. Paris, Julliard, 1968 e no campo mais recente da historia cultural G. GIUCCI, Viajantes do maravilhoso, o Novo Mundo. SP, Cia das Letras, 1992, L. MELLO e SOUZA, O Diabo e a Terra de Santa Cruz: Feitiçaria e religiosidade popular no Brasil colônia. SP, Cia. das Letras, 1994. 
dos Trópicos que foi tão vem foi retratadas nos relatos de missionários e viajantes assim como na pintura e na literatura.

Ampliando a idéia simmeliana ${ }^{27}$ da cidade e de sua arquitetura como uma obra de arte, proponho a idéia de que as paisagens urbanas das cidades brasileiras podem muito bem ser pensadas no corpo das formas expressivas do estilo barroco adotadas para o campo das artes plásticas e da arquitetura no Brasil e todo o seu cortejo de símbolos, os quais navegam na contramão das regras do pensamento ocidental clássico, e onde o absurdo da estetização das massas e do grotesco avança sobre a idéia da coerência, o mítico sobre o lógico, o imagético sobre o racional.

Tendência para tencionar o limite e provocar o Excesso eis aí uma das marcas de uma modalidade de controle simbólico do tempo afeta a América barroca e aos seus habitantes. Sem dúvida, é na não centralidade do centro cósmico organizador de onde nasce o teatro da vida urbana local que se compõe, de muitas formas, o caráter de monstruosidade e excentricidade de homem brasileiro e de suas cidades. Neste sentido é que considero importante de se investir na construção de novas formas de investigação no âmbito da memória e do patrimônio a partir dos estudos do cotidiano e do imaginário para se pensar as grandes metrópoles contemporâneas no Brasil.

Não se pode enfrentar este desafio senão a partir da construção de novos experimentos etnográficos de pesquisa no meio urbano do Brasil capaz de provocar novas indagações epistemológicas acerca do "savoir-faire" antropológico para a compreensão do hibridismo das formas que configuram os fenômenos culturais das suas grandes cidades. Procurando-se evitar um "colonialismo intelectual" que significa a transposição de métodos e técnicas de estudos do mundo urbano oriundos de centros de produção científica europeus, trata-se aqui de se investir na busca de novas autorias e autoridades no âmbito da representação etnográfica das paisagens urbanas do país, adotando-as como objetos temporais.

Esquivando-se da pressão da história imediata das transformações urbanas, a estética da desordem que configura as cidades brasileiras e suas imagens da monstruosidade, da deformidade e do bestial prova aqui do comportamento estético e da personalidade étnica de um povo que tem conseguido diante da agitação temporal encontrar repouso na adaptabilidade ${ }^{28}$ inspirado na técnica da viagem - do movimento na imobilidade, do equilíbrio na instabilidade - propagada pela figuras

${ }^{27}$ Cf. o autor, G. SIMMEL, Las ruínas, In: Cultura femenina y otros ensayos, Madrid, Revista de Occidente, 1934, p. 213 , em seu ensaio sobre as ruínas "la arquitectura es el único arte em que se apacigua y aquieta la grand contienda entre la voluntad del espítiru y la necessidad de la naturaleza: em la aruitectura llegan a perfecto equilibro dos tendencias contrarias: la del alma, que aspira hacia arriba, y la pesantez, que tira hacia abajo"

${ }^{28}$ A propósito de uma reflexão sobre as estruturas da imaginação e o tema da memória coletiva, ver G. BACHELARD, $L a$ dialétique de la durée. PUF, Paris, 1989.Ver igualmente G. DURAND, Les structures anhtropologiques de l'imaginaire Paris, DUNOD, 1984. 
heróicas do Navegador e do Aventureiro no imaginário popular, traduzido pelo pensamento intelectual erudito e letrado, e que versa sobre o mito de fundação da América. ${ }^{29}$ Sim, a técnica da viagem como forma de domesticar simbolicamente o tempo! O esquema cíclico de destruição e reconstrução, através do drama mítico da Morte e da Ressurreição da vida urbana, eternizou nos seus habitantes a técnica da viagem operada pelas figuras do Missionário, do Peregrino, do Navegador na imaginação popular.

\section{Etnografia da duração, memória dos passos perdidos.}

Portanto, é preciso se adentrar o tema da agitação temporal ${ }^{30}$ nos Trópicos para se re-conhecer que é o "trabalho" humano sobre os contornos dos grandes centros urbano-industriais uma das marcas do corpo coletivo no Brasil, cujo pulsar de nascimento, morte e do renascimento leva constantemente a pulsão da vida social ao limite de seu sistema. Sem dúvida, as cidades brasileiras possuem uma rítmica singular, elas pulsam onde as imagens da monstruosidade e do excesso expõem intelectuais locais à crise de suas categorias de interpretação.

O caso das pesquisas etnográficas mais recentes em torno da cultura do medo, da violência e da criminalidade nos grandes centros urbanos brasileiros é aqui significativo do que se acaba de afirmar, e suas reflexões precisariam ser incluídos como parte dos estudos sobre memória e patrimônio no país. ${ }^{31}$ Quando falamos de patrimônio e memória, não se pode afastar a retórica da morte nas ruas nas afecções paisagistas das cidades brasileiras da exuberância festiva em suas avenidas e da efervescência das trocas sociais em bares e botequins que reina na vida quotidiana de seus habitantes. Neste ponto, o barulho, o frenesi, a agitação fazem das paisagens urbanas das cidades brasileiras a condição temporal da perpetuação dos arranjos assimétricos da vida transcorrer entre seus habitantes: lugar de mortes e reencarnações, nem sempre em igual proporção para ricos e pobres, negros e brancos, homens e mulheres, adultos ou crianças.

Repensar novas formas de registro, documentação, apropriação e criação de memórias coletivas no corpo do patrimônio etnológico de uma comunidade urbano significa restituí-las no contexto dos itinerários de seus grupos sociais e no interior do tecido complexo das tramas urdidas no microcosmo da vida urbana. O desafio que me coloco é pensar a leitura/interpretação das paisagens urbanas e de

29. Cf. A respeito algumas obras já clássicas tais como S. GRUZINSKI, e C. BERNAND, Le Nouveau Monde, de la découverte à la la conquête. Paris, Fayard, 1991, P. CHAUNU, Les Amériques. Paris, A. Colin, 1972, T. TODOROV, La conquête de lÁmerique. Paris, Seuil, 1992, R. PEBAYLE, Les brésiliens, pionners et bâtisseurs. Paris, Flammarion, 1989, R. MORSE, O espelho do próspero. Säo Paulo, Cia das Letras, 1988, F HARTOG,. (org) Le Nouveau Monde. Paris, Les Belles Letres, 1992, J. MAGASICH-AIROLA \& J-M de BEER, América mágicaSP, Paz e Terra, 200, entre outros.

${ }^{30} \mathrm{Cf}$. expressão de G. BACHELARD, La dialectique de la durée. PUF, op. cit..

${ }^{31}$ Neste enfoque de pesquisa acerca da civilização urbana no Brasil incorporam-se muitas das reflexões de G. VELHO acerca dos estudos do individualismo, da subjetividade e do projeto social no corpo das sociedades complexas, modernas, urbano-industriais. 
suas afecções a partir da expressão de duas estéticas complementares (a do pormenor e a do fragmento $^{32}$ ) na forma através das quais os habitantes costumam operar com a intimidade dos instantes do seu dia-a-dia na tessitura de suas pratica cotidianas.

Considerando-se o microcosmo social como resultante do pulsar rítmico dos instantes vividos por seus há habitantes no dos territórios da vida urbana, numa grande metrópole, penso que o estudo da poética do pormenor que envolve uma estética de "alta-fidelidade" da vida quotidiana dos habitantes das grandes cidades tanto quanto da poética do fragmento me permitiria ultrapassar as macro-narrativas acerca da vida urbana, e adentrar a duração intima que encerram as praticas urbanas de seus habitantes e seus enraizamentos em certos territórios, evitando, assim, a ordem do discurso acerca da cidade em sua forma hipostasiada. ${ }^{33}$

Assim sendo, a Cidade se oferece como obra coletiva em sua expressão temporal descontinua o que implica para o etnógrafo uma proposta de interpretação que supere aquela unicamente regida por seus valores/categorias axiológicas. ${ }^{34}$ Para se compreender o desvio na estética contemporânea que toma forma na Cidade "tropical", é imprescindível que se contemple numa pesquisa em torno da memória coletiva, patrimônio etnológico e estética urbana no Brasil as transformações morfológicas validas de formas de vida social no interior de um estilo de civilização.

$\mathrm{N}$ a condição de antropólogo social não consigo compreender, metodologicamente, o sentido de uma pesquisa etnográfica no contexto urbano no Brasil simplesmente remontando a história linear de estilos de "viver a cidade" de seus habitantes, segundo periodização vazia de seus espaços no tempo. É necessário cotejar o tempo do mundo com o estudo do tempo vivido ${ }^{35}$, da sobreposição e consolidação de ritmos e instantes que regem a vida de seus habitantes, em seus apelos às diversas tradições urbanas que estão em competição entre si e delimitam, no tempo presente, a estética do caos que confere a 'aura “tropical” às cidades do Brasil.

Há, sem dúvida, uma a presença de morfologias estáveis nas manifestações paisagísticas das cidades "tropicais", morfologias com forte apelo estético à ordem e à simetria na configuração do fenômeno urbano do Brasil tanto quanto morfologias irregulares e instáveis que desvelam as razões ocultas do simbolismo de suas formas informes. Mais do que isto, há uma solidariedade convergente imensa entre elas. Neste sentido, o ponto de partida da adoção metodológica para se pesquisar o

\footnotetext{
${ }^{32}$ Cf. O.CALABRESE, A idade neobarroca. Lisboa, Edições 70.

${ }^{33}$ Idem.

${ }^{34}$ Cf. a inspiração das obras sempre férteis de P. SANSOT, La poétique de la ville. Paris, Klincksieck, 1972, de Cf. PETONNET, Espaces habités, ethnologie des banlieues. Paris, Galilée, 1979 e A. MOLES, Le Labyrinthe du vécu. Paris, Mériidiens, 1984

${ }^{35}$ A propósito ver G. BACHELARD, La dialectique de la durée. Paris, PUF, 1989.
} 
patrimônio etnológico das cidades brasileiras deve ser o jogo de luz e sombras entre passado e futuro como meios de expressão do comportamento estético do corpo coletivo no Brasil.

$\mathrm{O}$ caráter contraditorial das afecções paisagísticas ${ }^{36}$ que exalam os grandes centros urbanos do Brasil é em si mesmo, um elemento inquietante de qualquer pesquisa centrada em torno da memória do cotidiano e da fuga do tempo em seus territórios. A questão mais embaraçante trata do desafio de construir técnicas e procedimentos de investigação capazes de captar o "viver em cidades" no Brasil a partir de seus parâmetros não-racionais, isto é, dos sonhos, dos devaneios e do prazer dos sentidos que a cidade desperta em seus habitantes. ${ }^{37}$ Do folclore e do hedonismo popular às produções de uma cultura artística de elite, do espetáculo político às paradas eleitorais, da celebração dos calendários esportivos e musicais às festas religiosas, da exacerbação do corpo em espetáculo às delícias do consumismo; da proliferação de seitas religiosas e de cultos à ressurgência de movimentos regionais e locais, o que se depreende é que das paisagens urbanas do Brasil se traduz numa espécie de santuário da desordem. Um território capaz de celebrar, para além da materialidade dos objetos, dos hábitos, dos modos de vida de seus habitantes, o genius loci de um povo.

$\mathrm{Na}$ determinação de critérios para uma investigação dos dados sensíveis que conformam o fenômeno urbano do Brasil, e as suas "cidades tropicais", não se pode escapar a compreensão do conjunto de situações interativas feitas de emoções, de afetos, de sensações que constituem strictu sensu os cenários e os dramas sociais que descortinam as grandes cidades do país.

Re-situado no interior de uma etnografia da duração, submete-se as discursividades sobre patrimônio as dinâmicas culturais que orientam as formas de trocas sociais entre os habitantes no interior de uma grande metrópole, das suas práticas quotidianas, dos seus jogos de memória. Abandona-se a concepção de patrimônio no sentido de representar as "evidenciais materiais da história" da Cidade, para se refletir sobre o ato de destruição/criação de suas formas como parte de um procedimento interpretativo de seu acervo patrimonial.

A proposta é a exploração dos "cenários da memória" dos habitantes da cidade como condição que integra as ações e gestos de preservação patrimonial de seus territórios, alertando-se para a importância do ato compreensivo da experiência mnésica e fabulatória dos grupos urbanos em itinerância para se pensar a construção de suas alteridades na vida coletiva nas grandes aglomerações do país.

\footnotetext{
${ }^{36}$ Apropriação livre das idéias de P. SANSOT desenvolvidas pelo autor no artigo L'affection paysagère. In : Mort du paysge? Philosophie et esthétique du paysage. (org) François DAGOGNET, Seyssel, Champ Vallon, 1982.

${ }^{37}$ A inspiração aqui é a obra de Maffesoli, M. Aux Creux des apparences, evrs une éthiaue de l'ésthétiaue, Paris, Plon, 1992.
} 
Em termos de procedimentos metodológicos a imersão do etnógrafo na memória dos passos perdidos $^{38}$ dos moradores das grandes cidades como topos significativo da re-recriação de tradições urbanas. As paisagens urbanas despontando como espaços fantásticos onde os moradores de um grande centro urbano, habitando suas lembranças passadas, fazem das imagens imateriais de seu acervo patrimonial um conhecimento em ato da Cidade. ${ }^{39}$

\section{Do tempo vivido ao tempo pensado: a dialética da duração}

Trata-se, sobretudo de investigar os itinerários de vida de indivíduos e/ou grupos urbanos que traduzem as projeções subjetivas de uma memória coletiva enquanto processo de adaptaçãoacomodação de seus desejos de agir sobre o fundo de sentido das tradições urbanas.

Enfocando-se as tradições populares, as práticas culturais cotidianas nos bairros e as festas e rituais coletivos nas ruas e praças, o que se busca não são os traços autênticos de signos culturais de uma cultura urbana, pois se admite que a redução do "traço" mnésico a um signo cultural acaba por destituir o patrimônio etnológico de uma comunidade do seu poder de fabulação, de re-invenção da vida coletiva.

Em face dos processos de universalização/fragmentação em nossas modernas cidades industriais e sua lógica de destruição de antigas paisagens urbanas substituídas por outras, pensar a memória cotidiana na contemporaneidade me impõe outro desafio, o do conhecimento das motivações simbólicas dos gestos que encadeiam a morte e o renascimento da vida coletiva nas grandes metrópoles contemporâneas do Brasil. Motivações as quais provocam em seus habitantes a operação de recordar ou lembrar de um objeto, imagem ou relato que compõem o conjunto do patrimônio histórico e cultural meio urbano vivido por ele em sua trajetória social.

Neste sentido, todo o esforço transparece no ato de se registrar as memórias narradas de uma cidade pela voz de seus habitantes. Neste ato de narração se esconde o desafio do etnógrafo compartilhar com o próprio narrador as memórias da intimidade das situações e instantes por ele vividos nos territórios urbanos, em companhia ou não de outros habitantes do lugar. Um ato de pensar em tripla potencia (pensar um pensamento que se apresenta pensando as intensidades descontinuas dos instantes) e que, por isto, mesmo não se trata de uma lembrança-vestígio, dado imediato da consciência, mas se afirma como ato mediado pela fabulação o que faz com que cada episódio banal evocado pelo narrador se propague como matéria viva das tradições desta cidade. O processo de morte e renascimento de uma cidade, os ritos de destruição e reconstrução, o suplicio de sua matéria terrestre

${ }^{38}$ Cf. M. DE CERTEAU, A invenção do cotidiano. Petrópolis, Ed. Vozes, 1996.

${ }^{39}$ Ver a respeito G. DURAND, Les structures anthropologiques de l'imaginaire. Paris, Dunond, 1984. 
são assim um campo fértil de analise das representações simbólicas acerca do Tempo no mundo urbano contemporâneo. ${ }^{40}$

Portanto, parte do resgate dos signos culturais de uma Cidade, portanto, encontram-se presentes no momento de explicitação, para os seus habitantes, dos atos de destruição que conduziram ao extermínio de alguns de seus territórios, e que atua nos jogos entre lembranças e esquecimentos tramados pela memória de tais lugares. Mergulhar no labirinto dos signos culturais construídos nos jogos da memória, dos habitantes das cidades brasileiras sob a ameaça constante do urbanismo de "buldozzer" e de política públicas que encaram a Cidade como "cena vazia" a espera da representação, é desvendar as ações rotineiras "passadas" de uma comunidade urbana na sua busca de solução para problemas novos que o tempo depositou.

\section{O pleno vazio dos instantes, a memória e os lugares de lembrança.}

Para, além da eterna agonia da matéria terrestre, nas grandes cidades os moradores são capazes de recriar novas (em gestos e pensamentos) regras de ação e novas condutas para enfrentar as novas situações propostas por um ambiente urbano em constante mutação. A operação de "reconstituirão do passado" de uma cidade é, portanto, um processo ontológico que remonta as fontes arqueológicas do nascimento de uma comunidade urbana uma vez que através desta operação que seu corpo coletivo coloca em jogo, através de um dispositivo simbólico, o desafio de sua inserção espaço-temporal no mundo. ${ }^{41}$

Interpretar as origens dos signos culturais que delineiam paisagens urbanas é procurar responder a uma interrogação ontológica, ou seja, como o ser de uma comunidade tramou, em seus territórios, os fios do tempo. Isto significa que a Antropologia urbana deve contemplar em seus estudos sobre o mundo urbano contemporâneo os dispositivos simbólicos através dos quais os grupos e/ou indivíduos vivendo suas vidas cotidianas, conseguem atravessar a poeira do Tempo e resistir a sua matéria perecível.

Valorar positivamente o "vazio" da memória e não fazer da Cidade um lugar do esquecimento de signos culturais, mas sim um espaço poético, um espaço amigo, ${ }^{42}$ lugar de devaneios e criação de símbolos, não de negação da destruição e do desaparecimento, tem-se ai um grande desafio.

Para enfrentá-lo torna-se fundamental considerar a decomposição das paisagens urbanas (tratando-se a memória como estudo da temporalidade e não da historicidade) como parte dos estudos

\footnotetext{
${ }^{40}$ A propósito escrevi o artigo A irracionalidade do belo e a estética urbana no Brasil In: Territórios do cotidiano, uma introdução a novos olhares e experiências (orgs) Z. MESQUITA e C. R. BRANDÃO, Editora da UFRGS, Porto Alegre1995.

${ }^{41}$ Ver a respeito A. LEROI-GOURHAN, A. Le geste et la parole, la mémoire et les rithmes, Paris, Albin Michel, 1965.

${ }^{42}$ G. BACHELARD, La poétique de l'espace, Paris, PUF, 1989
} 
etnográficos e etnológicos sobre memória coletiva no mundo urbano contemporâneo, ou seja, sob a perspectiva dos arranjos e enquadres da descontinuidade do Tempo no coração dos relatos de seus habitantes.

O estudo das grandes cidades contemporâneas tem ensinado aos antropólogos que pensar seus espaços desde a "racionalidade" do tempo histórico, linear e evolutivo, em seu cortejo à monumentalidade, significa traduzir a cidade como paisagem repleta de objetos-mortos. Abandonandose a "racionalidade da ação" na conformação das cidades modernas, urbanas e industriais e pensando-a em confronto com o agenciamento do tempo "em situação", entra finalmente em cena o movimento de decomposição como problema para se pensar os seus territórios desde o grau do vivido humano que eles traduzem. ${ }^{43}$

A decomposição de prédios, a destruição de ruas, a mutação da paisagem de um bairro, enquanto experiências dramáticas para os habitantes de uma grande cidade conservam a possibilidade do relato, da história, revelando-se uma situação de conhecimento em ação a ser reconhecido e interpretado. Se a memória de uma cidade é, por um lado, monumental, por outro, ela é vivida no percurso quotidiano das ruas e praças. Resgatar os itinerários destas memórias como espaço de encenações da vida coletiva de um grande centro urbano significa colocá-los no bojo da própria gênese do seu patrimônio etnológico.

Isto porque se reconhece que a Cidade moderna longe de ser um objeto-depósito, aqui no caso um objeto temporal, possui a capacidade de absorção de todas as histórias dos grupos humanos que ali se depositaram, de dissolução de seus signos culturais, que se tornam, então, objetos etnográficos, prétextos de geração de novos experimentos etnográficos.

\section{Sobre as cidades ao sul do Brasil e a poeira do tempo}

Através do estudo da configuração da estética urbana no sul do Brasil e dos gestos que engendraram a instalação das cidades no interior da memória coletiva da sociedade brasileira, procurou-se pensar a incessante transformação das formas de vida social no mundo urbano contemporâneo e a infinidade de conteúdos simbólicos que se colocam em jogo no processo de destruição de uma cidade.

Há, no estudo do processo de destruição e reconstrução das grandes cidades no Brasil uma singularidade específica, a saber: o desafio de se interpretar a cidade como ruína e fragmento através do ponto de encontro entre, de um lado, a voracidade da civilização para domesticar a matéria terrestre no

${ }^{43}$ A propósito ver os comentários de G VATTIMO sobre o pensamento frágil em Les aventures de la différence Paris, Editions Minuit, 1985. 
Brasil, pacificando-a através da construção de paisagens urbanas ${ }^{44}$ e, de outro, desde a instalação da civilização urbana, a incompreensível adesão dos habitantes ao sacrifício de destruição de seus territórios de vida em permanente mutação.

As duas ações traduzem a singularidade do processo de destruição criativa que marca a existência dos territórios das cidades brasileiras, e que este pode ser enfocado a partir do princípio da poética da instabilidade. O que se quer dizer com isto? É que o fenômeno da eterna destruição e reconstrução das cidades brasileiras pode ser visto sob a ótica da forma como os habitantes renovam o seu passado urbano.

Desde o começo dos tempos, no Brasil, as utopias urbanas do passado europeu serviram como uma espécie de depósito de formas e conteúdos esparsos através dos quais os habitantes desta parte do mundo aprenderam a relacionar-se a sua matéria terrestre.

No Brasil, para a vida urbana perdurar no Tempo tornou-se necessário que suas estruturas espaciais retratassem a ondulação temporal vivida por seus habitantes. Para o bem ou para o mal é a vontade coletiva de enquadrar a agitação temporal na ordem do vivido e de formalizar, em seus territórios, a fuga do tempo àquilo que atribui a Cidade-ruína ${ }^{45}$ no Brasil um caráter de obra em perpétua criação. Isto certamente se refere às formas de agenciamento temporal que acompanham a formação das cidades brasileiras onde o teatro da vida urbana se apresenta como eterna possibilidade de re-inventar as distopias do passado, em sua liberdade de reiniciar a projeção do novo, do atual.

Em se tratando de uma estética urbana pautada pelas distopias do passado o que se pode observar no Brasil é que a Cidade-ruína serve como expressão do conjunto de intenções e de comportamentos de homem brasileiro diante do Tempo. Ou seja, mediante a destruição do arcaísmo de estruturas espaciais, os habitantes das cidades valorizam o presente na reformulação o passado. Não se pode compreender, portanto, a singularidade dos atos de destruição e reconstrução de um espaço de existência senão admito que os mesmos nascem dos atos, volições e sentimentos que a matéria terrestre de certos territórios desperta na imaginação simbólica dos seus habitantes.

Neste sentido, pode se interpretar a cidade eternamente destruída e reconstruída como uma matéria supliciada. Fruto da potência subterrânea de uma imaginação criadora presente ao homem brasileiro que imagina que ao destruir sua morada, consegue "domesticar" o Tempo. O fenômeno

\footnotetext{
${ }^{44}$ No sentido aqui do termo cunhado por N. ELIAS, Le société des individus, op. cit.

${ }^{45}$ Novamente apoio-me aqui em G. SIMMEL e em seu ensaio sobre as ruínas, cf. Segundo o autor: "En la coodinación de naturaleza y espítiru suele seguirse uma jerarquía cósmica que considera la naturaleza como el cimiento, la materia prímera o a médio elaborar y el espíritu como la cima y corona, como actividad que imprime la forma definitiva. Pero la ruína invierte este orden, puesto que en ella el acabado producto espiritual sucumbe ahora a las mismas fuerzas que trazaron el perfil de la montana y lar ibera del rio." Observo aí o quanto a ruína restitui aquele que a contempla a intuição do instante e, por derivação, a experiência com o tempo descontínuo, nos termos bachelardianos.
} 
incessante da destruição criativa que atinge as cidades brasileiras desde suas origens, me obriga como antropóloga a proceder às diferenças entre a causalidade formal e a causalidade para a interpretação das estruturas espaços-temporais que singularizam as formas do viver urbano em seus territórios.

Sob o ângulo restrito de uma causalidade material como interpretação dos efeitos da agitação temporal no interior da consolidação do fenômeno urbano no Brasil se acabaria por reduzir a experiência temporal dos habitantes de uma grande metrópole às rupturas vividas por eles na extensão de sua matéria. O dito popular do Brasil como país sem memória estaria posto como chaveinterpretativa. Por outra via, do ponto de vista de uma causalidade formal, teríamos a chance de perceber que a instalação da civilização urbana no Brasil e sua perene re-fundação esta mais diretamente ligada ao esforço de seus habitantes em perdurar no tempo, sendo a adesão a sua matéria perecível uma forma de atingir a imortalidade.

Assim, ao invés de se apontar para a historia das veleidades tecnicistas que orientaram a fundação das cidades no Brasil; de se ordenar uma seqüência material de acontecimentos econômicos e políticos para explicar o gesto predatório do da figura do homem urbano no Brasil; antes de se atribuir uma feição decadente às paisagens urbanas brasileiras, o que se propõe é a compreensão do comportamento estético e da personalidade étnica das comunidades urbanas do país diante das feições do Tempo.

Trata-se de adotar uma perspectiva compreensiva para interpretar o ato perpétuo de destruição e reconstrução da cidade que acompanha a criação da civilização urbana na América tropical, por alguns historiadores aceita como "barroca". A personalidade confusional da civilização nos Trópicos talvez nos ajude aqui a entender melhor minha proposta de abordar a cidade como objeto temporal, configurada segundo a ordem impressa por uma coletividade ao conjunto disperso de momentos que esta vive no Tempo.

Afastando-me progressivamente da causalidade material que orientou o pensamento social brasileiro na interpretação das paisagens urbanas brasileiras (muitas vezes atingidas pela valoração negativa de decadentes), recorro à idéia bachelardiana da causalidade formal para pensar o campo dos estudos do patrimônio e da memória nas grandes cidades do Brasil, ou seja, como fenômenos relacionados ao conjunto de motivações simbólicas e das intimações sociais vividas por suas comunidades urbanas em relação ao Tempo e que resultaram numa estética da ruína e da desordem para teatro da vida urbana no país.

Certamente para aderir a tal forma de interpretação devo abdicar de uma pretensa interpretação realista dos fenômenos urbanos no Brasil advinda das influencias de uma sociologia positiva na compreensão da vida social nos grandes centros urbanos do país. Sob o enfoque aprioristico, a Cidade 
tropical aqui não consegue jamais atingir o estatuto de um fenômeno que condensa uma seqüência histórica, linear e cumulativa de procedimentos colocados em pauta pelo homem da civilização no Novo Mundo.

Ao invés, portanto, de pesquisar as causas ultimas do processo histórico e social de instalação da civilização urbana nos Trópicos, aceito o desafio de conduzir a bom termo a compreensão microscópica da tessitura da vida urbana em seus territórios a partir dos itinerários, das trajetórias sociais e das formas de sociabilidade dos grupos que neles habitam na tentativa de esclarecer que ela se impõe como matéria continua justamente pela eficácia dos atos sociais dos seus habitantes. Ao ecoar nos instantes presentes as lembranças do passado afrontam a ausência possível no futuro em um esforço para modelar sua existência recomeçasse-se novamente a tradição que ao propagar-se lhe dá uma aparência de continuidade a ser projetada para o futuro.

Sob a ótica das dinâmicas da cultura, a destruição de ruas, as ruínas de edificações, os fragmentos de sociabilidades arcaicas, a reconstrução da paisagem dos bairros, o crescimento da cidade informal; tudo faz das cidades brasileiras a imagem do sofrimento e do caos pelo caráter descontinuo de suas formas informes. Entretanto, nada nos impede de pensar a edificação de novos lugares urbanos e demolições de antigas estruturas espaciais são, portanto, obras da sinergia dos devaneios da vontade e do repouso que nutre uma comunidade em relação ao seu devir.

Para se superar os limites da imagem da catástrofe e do caos na interpretação das paisagens urbanas e suas afecções no Brasil, é que concebo o conjunto civilizacional das cidades brasileiras como o resultado da recriação orgânica de um querer-viver coletivo no Tempo capaz de estabelecer uma composição duradoura entre seus elementos espaciais dispares.

A Cidade no Brasil não pode ser vista, assim, simplesmente por sua solidez material. Tramada na urdidura descontínua dos instantes desde os primeiros embriões de vida urbana nos Trópicos, a Cidade é vista aqui, acima de tudo, como espaço fantástico onde se manifesta um perpétuo recomeçar de um querer-viver coletivo.

É, portanto um fenômeno de consolidação temporal aquela que vai definir finalmente a tonalidade estética "decadente" e "monstruosa" dos grandes centros urbanos do Brasil face às transformações precipitadas na sua superfície terrestre das ultimas décadas do século XX, a implantação das redes rodoviárias de transporte de mercadorias, de pessoas e energias, transporte aéreo e terrestre, substituindo os antigos trens e navios, a extensão desordenadas de cidades e vilarejos, transformação da agricultura, infra-estrutura turísticas e a fisionomia do ambiente que nos rodeia.

As barragens, os tetos dos edifícios, os canais, os túneis, as grandes auto-estradas, as centrais elétricas, as usinas termonucleares, as estações de trem, os aeroportos, etc. Lá onde a realidade material 
da civilização urbana e industrial no Brasil se descortina como descontinuidade efetiva, eu posso descobrir a construção de uma conduta de continuidade própria a um querer-viver coletivo que nada mais deseja que perpetuar-se no tempo.

Nesta ambiência de harmonia conflitual de um país que reúne em suas entranhas lugares tão díspares, a destruição e reconstrução das cidades no Brasil são temas complexos que envolvem, ao mesmo tempo, o arranjo estético das intenções e das ações de um corpo coletivo e a adesão global de uma comunidade em seus devaneios contra a Morte, sem que esta se contraponha necessariamente a própria matéria perecível do Tempo. É, portanto, no coração de tempos superpostos que nós devemos nos colocar para compreender o fenômeno da destruição como processo de construção perpétua do teatro da vida urbana do Brasil.

\section{A guisa de conclusão, e se tudo realmente começasse pelo fim?}

A destruição da Cidade no Brasil desempenha aqui um papel positivo: insere-se, portanto, no conjunto mítico que a América tropical veicula, ou seja, nos ritos de retomada do Tempo. Dito de outra forma, num esquema dinâmico, a cidade urbano-industrial de hoje reabilita e eufemiza a barbárie de ontem. Ao barbarismo canibal com que devoramos nossa própria casa atribuímos uma feliz promessa de uma nova ordem ressuscitada. Tornamo-nos, assim, os mestres de um movimento circular do tempo e de seus ritmos, movimento este que vai se transformar num talismã contra nosso destino de homens mortais.

Parafraseando G. BACHELARD, para melhor compreender a duração aberta afetando as paisagens urbanas das cidades brasileiras, patrimônio em perpetuo movimento de dissolução e de recriação, necessito conviver com um pensamento estético que reflete acerca das promessas do futuro na intimidade da descontinuidade temporal dos instantes. Talvez seja este o caso do comportamento estético do homem brasileiro em face de nossas cidades "sem formas" e sem obras cultivadas. 